\title{
Damage Characteristics of Zr-based Metallic Glasses under Helium Ions Irradiation
}

\author{
Fengjiang $\mathrm{Li}^{1, \mathrm{a}}$, Jianshuo Xing ${ }^{1, \mathrm{~b}}$, Ziqiang Zhao ${ }^{2, \mathrm{c}}$ and Bingchen Wei ${ }^{1, \mathrm{~d} *}$ \\ ${ }^{1}$ Institute of Mechanics, Chinese Academy of Sciences, 15 Beisihuanxi Road, \\ Beijing 100190, China \\ ${ }^{2}$ School of Physics, Peking University, 201 Chengfu Road, Beijing 100871, China.

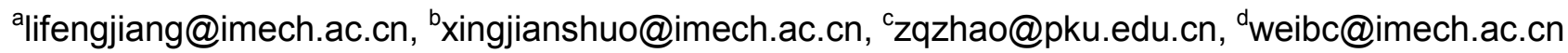

Keywords: Metallic glass, Ion irradiation, Structural stability, Damage characteristics.

\begin{abstract}
Metallic glasses (MGs) exhibit extremely high strength and superior resistance to corrosion. They are also supposed to be resistant against displacive irradiation due to their inherent disordered structure, and thereby are viewed as potential candidates for applications in irradiation environments. However, the structures and properties evolution of metallic glasses, especially bulk metallic glasses (BMGs), under irradiation has not been fully understood up to now. In this work, the structural stability and damage characteristics of a Zr-based BMG under helium ions irradiation environment were investigated. Meanwhile, the effect of structural relaxation and crystallization on the irradiation response of the BMG was also studied. Results show that the BMG reserves the amorphous structure within the studied range of fluence, and exhibits better irradiation resistance compared to that of the crystalline alloys. In our opinion, the initial free volume concentration affects the damage morphology of the BMG, while partial crystallization will lead to significantly embrittlement under irradiation.
\end{abstract}

\section{Introduction}

Metallic glasses (MGs), also named as glassy alloys, have drawn numerous attention since its discovery in 1960s for its unique mechanical and chemical properties, such as high strength, superior resistance to corrosion etc. [1]. MGs are potential candidates for applications in irradiation environments due to their inherent disordered structure [2]. The appearance of bulk metallic glasses (BMGs) have vastly increased their usefulness for structural applications [3-6] and created a renewed interest in these materials for nuclear applications [7-11]. A deuterium-tritium fusion reaction produces helium ions [12] with high energies and the helium ion bombardment of target materials can lead to damages, such as bubbling, peeling, flaking, and delamination at the peak zone of helium concentration under the surface layer. Till now, few studies have been done on the irradiation damage of BMGs upon $\mathrm{He}$ ion irradiation. Wang et al. reported that $\mathrm{Zr}_{64} \mathrm{Cu}_{17.8} \mathrm{Ni}_{10.7} \mathrm{Al}_{7.5}$, $\mathrm{Fe}_{80} \mathrm{Si}_{7.43} \mathrm{~B}_{12.57},\left(\mathrm{Cu}_{47} \mathrm{Zr}_{45} \mathrm{Al}_{8}\right)_{98.5} \mathrm{Y}_{1.5}$ and $\mathrm{Co}_{61.2} \mathrm{~B}_{26.2} \mathrm{Si}_{7.8} \mathrm{Ta}_{4.8}$ BMGs had better resistance to 500 $\mathrm{keV} \mathrm{He}^{2+}$ irradiation than the metallic tungsten [13-15]. Xu et al. studied the microstructural evolution of amorphous $\mathrm{Fe}_{79} \mathrm{~B}_{16} \mathrm{Si}_{5}$ alloy irradiated with $5 \mathrm{keV}$ or $150 \mathrm{eV} \mathrm{He}$ ions, and pointed that the formation of helium bubbles is related to the formation and migration of vacancy-type defects even in amorphous alloys [16]. Obviously, much more work, concerning different ion energies, fluences and alloy systems should be done to further understanding the damage feature and underlying mechanism of $\mathrm{He}$ ion irradiated BMGs. In this work, damage of $\mathrm{Zr}_{47.9} \mathrm{Ti}_{0.3} \mathrm{Cu}_{39.3} \mathrm{Ni}_{3.1} \mathrm{Al}_{9.4} \mathrm{BMG}$ under $30 \mathrm{keV} \mathrm{He}{ }^{+}$ion irradiation at a high fluence of $3 \times 10^{18}$ ions $/ \mathrm{cm}^{2}$ was investigated. Especially, the effect of structural relaxation and crystallization on the damage characteristics was also studied to explore the interaction between MGs and $\mathrm{He}$ ion. In addition, metallic $\mathrm{Zr}$ and $\mathrm{Zr}_{67} \mathrm{Ni}_{33}$ were studied for comparison.

\section{Experimental Procedures}

The Zr-based BMG with a nominal composition of $\mathrm{Zr}_{47.9} \mathrm{Ti}_{0.3} \mathrm{Cu}_{39.3} \mathrm{Ni}_{3.1} \mathrm{Al}_{9.4}$ (at. \%) were prepared by arc melting a mixture of elements with purity higher than $99.9 \%$ (at. \%). The ingot 
alloy was remelted and chill casted into a $5 \mathrm{~mm}$ cylindrical copper mold in a Ti-gettered argon atmosphere. The BMG rods were cut to $2 \mathrm{~mm}$-thick sections and polished to $1 \mu \mathrm{m}$ finish, prepared for irradiation. The alloy structure before and after irradiation was characterized by X-ray diffraction (XRD) using $\mathrm{Cu} \mathrm{K} \mathrm{K}_{\alpha}$ radiation. Thermal analyses of the specimens were performed in differential scanning calorimeter (Netzsch DSC 404C) at a heating rate of $20 \mathrm{~K} / \mathrm{min}$ under argon atmosphere. Relaxation and crystallization were obtained by isothermal annealing treatments at 651 $\mathrm{K}\left(T_{\mathrm{g}}-50 \mathrm{~K}\right)$ and $733 \mathrm{~K}\left(T_{\mathrm{g}}+20 \mathrm{~K}\right)$, respectively, for different duration. Pure $\mathrm{Zr}$ and $\mathrm{Ni}_{33} \mathrm{Zr}_{67}$ compound were also prepared as a comparison.

The polished specimens were irradiated with $30 \mathrm{keV} \mathrm{He}^{+}$ion beam at normal angle using a 4.5 $\mathrm{MeV}$ electrostatic accelerator with a fluence of $3 \times 10^{18}$ ions $/ \mathrm{cm}^{2}$. The dimensions of ion beam are $\sim 2 \times 1.5 \mathrm{~cm}^{2}$ during irradiation. SRIM program was carried for simulating the ions irradiation process to calculate the energy loss of the incident helium ions and the displacement damage in the target materials.

\section{Results and Discussion}

Irradiation-induced damage is usually evaluated by displacement per atom (DPA), which is estimated by the NRT formula [17]:

$$
d p a=\frac{0.8}{2 E_{d}}\left(\frac{d E}{d x}\right)_{n} \frac{\varphi_{t}}{\rho}
$$

where $\phi_{\mathrm{t}}$ is the ion fluence of incident ions per unit area, $\rho$ is the atomic density of the target material, $E_{\mathrm{d}}$ is the average displacement threshold of the target material. The weighted mean was taken as its displacement energy in case of the multi-element materials [18]. $(\mathrm{d} E / \mathrm{d} x)_{\mathrm{n}}$ is the linear energy loss per ion to the target by nuclear processes obtained from SRIM simulation.

Fig. 1 shows the depth-dependent curves of DPA for $\mathrm{Zr}, \mathrm{Zr}_{67} \mathrm{Ni}_{33}$ and $\mathrm{Zr}_{47.9} \mathrm{Ti}_{0.3} \mathrm{Cu}_{39.3} \mathrm{Ni}_{3.1} \mathrm{Al}_{9.4}$ BMG at the fluence of $3 \times 10^{18}$ ions $/ \mathrm{cm}^{2}$. The peak DPA, $(\mathrm{d} E / \mathrm{d} x)_{\mathrm{n}}$ and projected range are shown in Table 1. It is obvious that those three curves have the similar distribution of DPA owing to the similar average relative atomic mass and displacement energies. It also can be found that the DPA in Zr-based BMG increases rapidly under near surface. However, after reaching its peak before average projected range, the DPA of BMG will decline dramatically, and extend a short tail. This is because that the low energy $\mathrm{He}^{+}$ions lost its most energy during initial interactions and the rest energy isn't enough to knock away a metal atom.

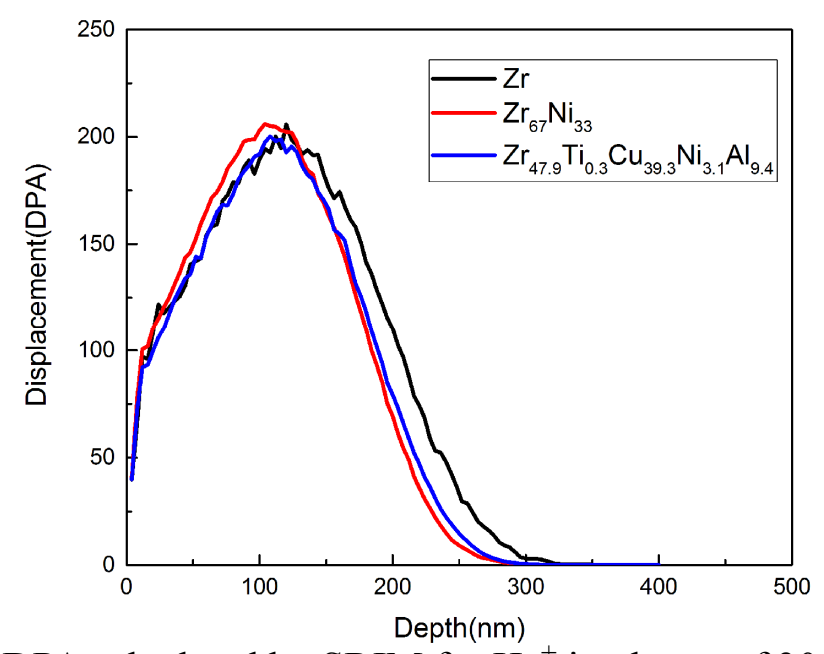

Fig. 1 Depth profile of DPA calculated by SRIM for $\mathrm{He}^{+}$ion beam of $30 \mathrm{keV}$ in $\mathrm{Zr}, \mathrm{Zr}_{67} \mathrm{Ni}_{33}$ and $\mathrm{Zr}_{47.9} \mathrm{Ti}_{0.3} \mathrm{Cu}_{39.3} \mathrm{Ni}_{3.1} \mathrm{Al}_{9.4} \mathrm{BMG}$ at the fluence of $3 \times 10^{18}$ ions $/ \mathrm{cm}^{2}$ 
Table 1 Results of SRIM program simulation

\begin{tabular}{|c|c|c|c|}
\hline Specimen & $\mathrm{Zr}$ & $\mathrm{Zr}_{67} \mathrm{Ni}_{33}$ & $\mathrm{Zr}$-based BMG \\
\hline Peak DPA & 193 & 205 & 200 \\
\hline$(d E / d x)_{\mathrm{n}}(\mathrm{eV} / \mathrm{nm})$ & 7.359 & 9.155 & 9.370 \\
\hline Projected range $(\mathrm{nm})$ & 141.8 & 126.4 & 131.8 \\
\hline
\end{tabular}

Fig. 2 (a) shows the XRD patterns of as-cast BMG, as well as the structurally relaxed BMG after different isothermal annealing treatments. As shown in Fig. 2 (a), the XRD patterns of the BMGs exhibit only broad diffraction peak without any other sharp Bragg peaks, confirming the fully amorphous structure at all states. Whereas as shown in Fig. 2 (b), Zr-based BMG still maintain their amorphous structure after a fluence of $3 \times 10^{18} \mathrm{He}^{+}$ion irradiation. In fact, the heating during $\mathrm{He}^{+}$ion irradiation is not obvious, where the surface temperature is elevated to about $100^{\circ} \mathrm{C}[19]$. This temperature is much lower than the glass transition temperature $\left(T_{\mathrm{g}}, 701 \mathrm{~K}\right)$ and crystallization $\left(T_{\mathrm{x}}\right.$, $770 \mathrm{~K}$ ) temperatures of the $\mathrm{Zr}_{47.9} \mathrm{Ti}_{0.3} \mathrm{Cu}_{39.3} \mathrm{Ni}_{3.1} \mathrm{Al}_{9.4} \mathrm{BMG}$, which is obtained from DSC tests (not shown here).
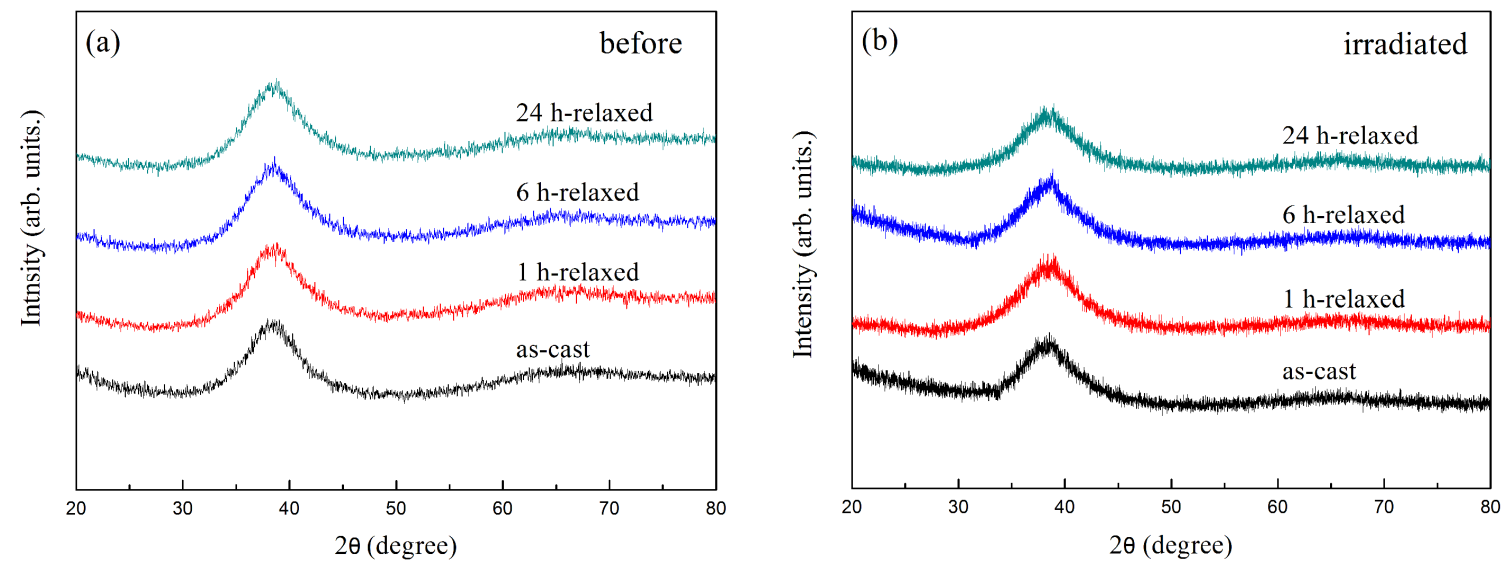

Fig. 2 XRD patterns for the as-cast and relaxed $\mathrm{Zr}_{47.9} \mathrm{Ti}_{0.3} \mathrm{Cu}_{39.3} \mathrm{Ni}_{3.1} \mathrm{Al}_{9.4} \mathrm{BMG}$

(a) before and (b) after $\mathrm{He}^{+}$ion irradiation at a fluence of $3 \times 10^{18}$ ions $/ \mathrm{cm}^{2}$

Fig. 3 shows the SEM images of surface morphology of pure $\mathrm{Zr}, \mathrm{Zr}_{67} \mathrm{Ni}_{33}$ and $\mathrm{Zr}_{47.9} \mathrm{Ti}_{0.3} \mathrm{Cu}_{39.3} \mathrm{Ni}_{3.1} \mathrm{Al}_{9.4} \mathrm{BMG}$. Three different kinds of responses to $\mathrm{He}^{+}$ion irradiation are found on specimen surfaces. Some dome-shaped bubbles form on $\mathrm{Zr}$ surface randomly. Serious peelings are the main damages on the $\mathrm{Zr}_{67} \mathrm{Ni}_{33}$ surface instead of bubbles. While for the BMG sample, lots of hole-damages and a few bubbles appear on irradiated surface. The mean diameter, area fraction and number density of the damages are also shown in Table 2. On the view of the area fraction of damage, the BMG has higher irradiation resistance than pure $\mathrm{Zr}$.

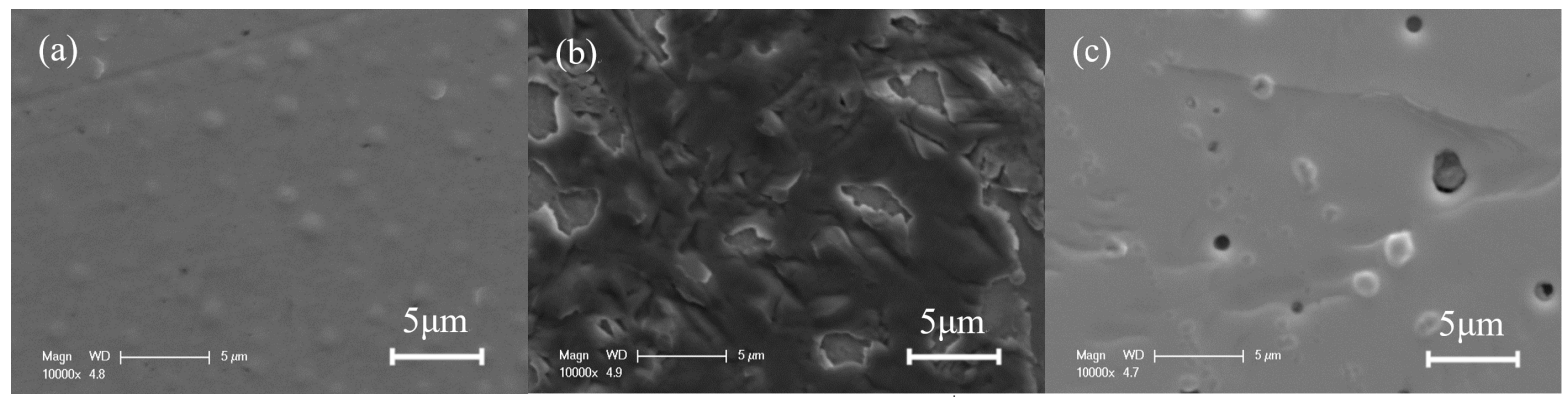

Fig. 3 SEM images for $30 \mathrm{keV} \mathrm{He}{ }^{+}$ion irradiated

(a) $\mathrm{Zr}$ (b) $\mathrm{Zr}_{67} \mathrm{Ni}_{33}$ (c) $\mathrm{Zr}_{47.9} \mathrm{Ti}_{0.3} \mathrm{Cu}_{39.3} \mathrm{Ni}_{3.1} \mathrm{Al}_{9.4} \mathrm{BMG}$

Generally, helium is small, inert and not soluble in metal materials, so helium ions injected in target materials migrate mainly by the following physical mechanisms [20]: (i) the migration of interstitial helium atoms occurs generally with very low migration energy; (ii) substitutional helium atoms may diffuse by a conventional vacancy-exchange mechanism; (iii) substitutional helium atoms may also migrate by dissociation mechanism. Gathered helium atoms form tiny bubbles, which are confirmed by experiments [21]. The bubbles prefer form on cracks located in irradiated 
layer when they reach a higher concentration. Evans [22] suggests that the pressure in cracks causes plastic deformation, which is called gas pressure model. While Eernisse [23] suggests that lateral compressive stress leads to the instability and bending of upper surface and the formation of bubbles is a release of stress. For both models, the material brittleness would determine the eventual surface morphologies, as the brittle materials apt to fracture during bending of the bubble surface. Here, the ductile pure $\mathrm{Zr}$ shows bubbles morphology, whereas $\mathrm{Zr}_{67} \mathrm{Ni}_{33}$ exhibits severe peeling due to its brittle nature and higher damage degree. The BMG are more brittle than $\mathrm{Zr}$ but more ductile than $\mathrm{Zr}_{67} \mathrm{Ni}_{33}$, therefore, it shows both bubbles and holes, in which the latter is caused by the rupture of bubbles. It should be noted that the damage area fraction of BMG is smaller than the other two crystalline metals, indicating a higher irradiation resistance for the amorphous alloy at the same irradiation environment.

Table 2 Damage parameters on specimens

\begin{tabular}{|c|c|c|c|}
\hline Specimen & Mean diameter $(\mu \mathrm{m})$ & Area fraction $(\%)$ & Number density $\left(/ \mathrm{mm}^{2}\right)$ \\
\hline $\mathrm{Zr}$ & 0.9 & 6.4 & 91065 \\
\hline As-cast BMG & 1.1 & 1.4 & 11154 \\
\hline 1 h relaxed BMG & 1.0 & 1.2 & 4825 \\
\hline 6 h relaxed BMG & 0.6 & 1.6 & 21568 \\
\hline 24 h relaxed BMG & 0.9 & 2.0 & 17673 \\
\hline Fully crystallized BMG & 0.5 & 1.2 & 61909 \\
\hline
\end{tabular}

The surface morphology of $\mathrm{Zr}_{47.9} \mathrm{Ti}_{0.3} \mathrm{Cu}_{39.3} \mathrm{Ni}_{3.1} \mathrm{Al}_{9.4}$ BMG in different relaxed states after $3 \times 10^{18}$ $\mathrm{He}^{+}$ion irradiation was also studied, as shown in Fig. 4. Dome-shaped bubbles and hole-damages appear on 1 h-relaxed BMG, similar to that of the as-cast one in Fig. 3 (c). For the BMG relaxed for $6 \mathrm{~h}$, the bubbles do not appear, instead, only holes form. Further increase of the relaxation time could not change the damage morphology obviously, but will bring a slight increase of damage area fraction. Previous studies have proved that structural relaxation corresponds to the annihilation of extra free volume during annealing, and leads to the BMG approaching a meta-stable equilibrium state. The increase of relaxation time contributes to highly relaxed state and thereby less free volume, which also gives rise to embrittlement of BMG [24]. The effect of relaxation on the damage morphology suggests that more free volume leads to formation of bubbles and less damage area fraction. On the other hand, highly relaxed state (less free volume) leads to the rapture of bubbles and lager damage fraction.

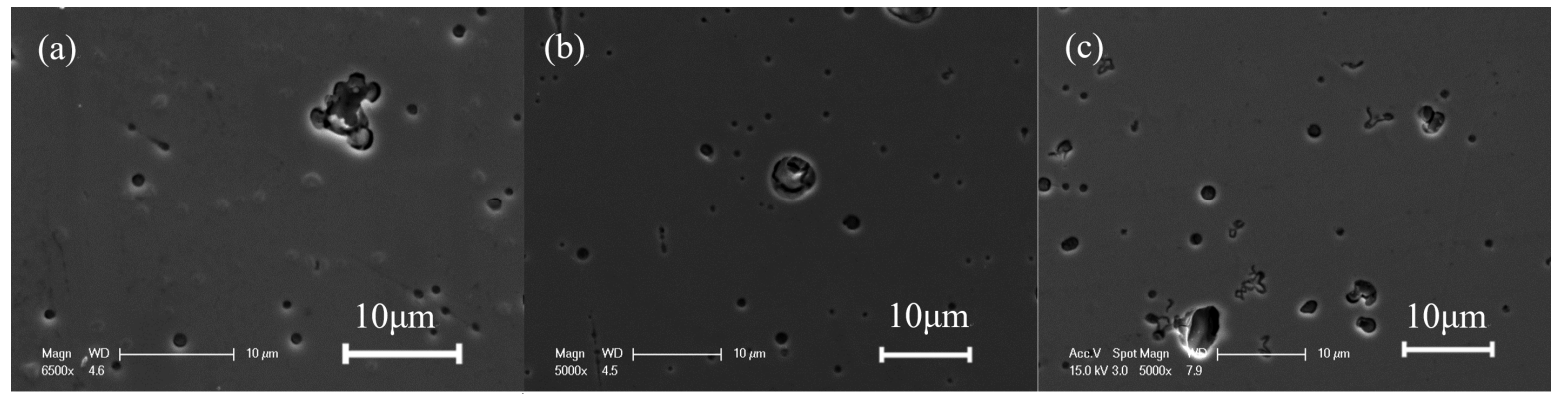

Fig. 4 SEM images for $30 \mathrm{keV} \mathrm{He}$ ion irradiated $\mathrm{Zr}_{47.9} \mathrm{Ti}_{0.3} \mathrm{Cu}_{39.3} \mathrm{Ni}_{3.1} \mathrm{Al}_{9.4} \mathrm{BMG}$ in different relaxed states (a) $1 \mathrm{~h}$ relaxed (b) $6 \mathrm{~h}$ relaxed (c) $24 \mathrm{~h}$ relaxed

To investigate the influence of crystallization on anti-irradiation performance, annealing was induced to obtain different crystallization fractions. The transformed crystalline fraction can be evaluated by measuring the residual area of the crystallization peak in the non-isothermal DSC curves obtained after annealing. The crystallization fractions $x(t)$ in the BMG can be estimated as:

$$
x(t)=\frac{\Delta H_{\text {cast }}-\Delta H_{t}}{\Delta H_{\text {cast }}} .
$$

where $\Delta H_{t}$ and $\Delta H_{\text {cast }}$ are the measured enthalpy release during the continuous heating with and without annealing treatment [25]. Fig. 5 shows the SEM images of $\mathrm{Zr}_{47.9} \mathrm{Ti}_{0.3} \mathrm{Cu}_{39.3} \mathrm{Ni}_{3.1} \mathrm{Al}_{9.4} \mathrm{BMG}$ with different crystallization fractions after $3 \times 10^{18} \mathrm{He}^{+}$ion irradiation. It can be observed that there 
are two kinds of damage on the $28 \%$ crystallized and $57 \%$ crystallized BMG: one is round holes as seen in the as-cast and relaxed samples, with the average diameter of about $1.2 \mu \mathrm{m}$; the other is peeling off areas with the size of tens micrometers. Fully crystallized specimens show uniform hole-damages and no peeling-off or bubbles. The results suggest that the $28 \%$ crystallized BMG has the worst irradiation resistance. The helium atoms preferentially gather at the interfaces between brittle crystalline and amorphous phases in partial crystallized BMG, therefore, lead to brittle fracture and collapse of the surrounded materials when the helium concentration and bubble pressure is high enough. While, fully crystallized specimens have no crystalline-amorphous interfaces, and exhibit an uniform damage morphology. Damage number density on pure $\mathrm{Zr}$ and fully crystallized specimens is obviously higher than as-cast BMG, indicating that BMGs are potential candidates for applications in irradiation environments.

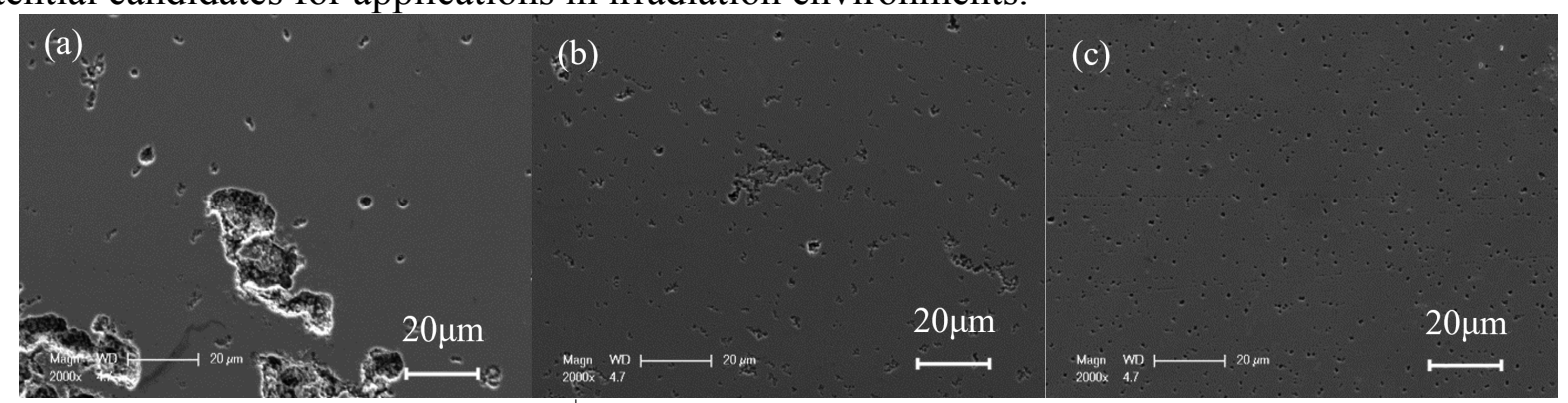

Fig. $5 \mathrm{SEM}$ images for $30 \mathrm{keV} \mathrm{He}$ ion irradiated $\mathrm{Zr}_{47.9} \mathrm{Ti}_{0.3} \mathrm{Cu}_{39.3} \mathrm{Ni}_{3.1} \mathrm{Al}_{9.4} \mathrm{BMG}$ with different crystallization fractions (a) $28 \%$, (b) $57 \%$, (c) $100 \%$

\section{Conclusion}

$\mathrm{Zr}_{47.9} \mathrm{Ti}_{0.3} \mathrm{Cu}_{39.3} \mathrm{Ni}_{3.1} \mathrm{Al}_{9.4} \mathrm{BMG}$ maintain its amorphous state after $30 \mathrm{keV} \mathrm{He}{ }^{+}$ion irradiation at a fluence of $3 \times 10^{18}$ ions $/ \mathrm{cm}^{2}$, indicating a high structural stability. Zr-based BMG is more $\mathrm{He}^{+}$ion irradiation resistant than $\mathrm{Zr}$ and $\mathrm{Zr}_{67} \mathrm{Ni}_{33}$. The effect of structural relaxation on the irradiation damage shows that higher initial free volume concentration corresponds to a higher irradiation resistance. Partial crystallization leads to the deterioration of the irradiation resistance due to the presence of crystalline-amorphous phase boundaries. BMGs are more irradiation resistant than the crystalline counterpart materials.

\section{Acknowledgements}

This work is financially supported by the National Nature Science Foundation of China (Grant No. 51071166, No. 51271193 and No. 11332011).

\section{References}

[1] W. Klement, R.H. Willens, P. Duwez, Non-crystalline structure in solidified gold-silicon alloys, Nature. 187(1960) 869-870.

[2] W.J. Weber, R.C. Ewing, C.A. Angell, G.W. Arnold, A.N. Cormack, J.M. Delaye, D.L. Griscom, L.W. Hobbs, A. Navrotsky, D.L. Price, A.M. Stoneham, W.C. Weinberg, Radiation effects in glasses used for immobilization of high-level waste and plutonium disposition, J. Mater. Res. 12(1997) 1946-1978.

[3] A. Inoue, X.M. Wang, W. Zhang, Developments and applications of bulk metallic glasses, Rev. Adv. Mater. Sci. 18(2008) 1-9.

[4] A. Greer, Y. Cheng, E. Ma, Shear bands in metallic glasses, Mater. Sci. Eng. R. 74(2013) $71-132$.

[5] M.D. Demetriou, M.E. Launey, G. Garrett, J.P. Schramm, D.C. Hofmann, W.L. Johnson, R.O. Ritchie, A damage-tolerant glass, Nat. Mater. 10(2011) 123-128. 
[6] W.H. Wang, C. Dong, C.H. Shek, Bulk metallic glasses, Mater. Sci. Eng. R. 44(2004) 45-89.

[7] A.G. Perez-Bergquist, H.B. Bei, K.J. Leonard, Y.W. Zhang, S.J. Zinkle, Effects of ion irradiation on $\mathrm{Zr}_{52.5} \mathrm{Cu}_{17.9} \mathrm{Ni}_{14.6} \mathrm{Al}_{10} \mathrm{Ti}_{5}$ (BAM-11) bulk metallic glass, Intermetallics. 53(2014) 62-66.

[8] X.N. Zhang, X.X. Mei, X. Ma, Y.M. Wang, J.B. Qiang, Y.N. Wang, $\mathrm{Ar}^{12+}$ induced irradiation damage in bulk metallic glass $\left(\mathrm{Cu}_{47} \mathrm{Zr}_{45} \mathrm{Al}_{8}\right)_{98.5} \mathrm{Y}_{1.5}$, Chin. Phys. Lett. 32(2015) 026801.

[9] F.Q. Gong, J. Wen, Y.J. Zhao, J.B. Qiang, Y.M. Wang, X.X. Mei, C. Dong, X.H. Wang, Stable reflectivity of bulk metallic glass mirrors for ITER optical diagnostic through an irradiation-induced self-recovery mechanism, J. Nucl. Mater. 429(2012) 221-225.

[10] Z. Hu, Z.Q. Zhao, Y.D. Wu, T. Lu, J.S. Xing, B.C. Wei, Surface features of Zr-based and Ti-based metallic glasses by ion irradiation, Vacuum. 89(2013) 142-146.

[11] Z. Hu, Z.Q. Zhao, Y.P. Hu, J.S. Xing, T. Lu, B.C. Wei, Effect of ion irradiation on mechanical behaviors of $\mathrm{Ti}_{40} \mathrm{Zr}_{25} \mathrm{Be}_{30} \mathrm{Cr}_{5}$ bulk metallic glass, Mater. Res-Ibero-am. J. 15(2012) 713-717.

[12] K. Morishita, R. Sugano, B.D. Wirth, MD and KMC modeling of the growth and shrinkage mechanisms of helium-vacancy clusters in Fe, J. Nucl. Mater. 323(2003) 243-250.

[13] B. Wang, X.X. Mei, W.J. Hou, Y.N. Wang, Z.G. Wang, C. Dong, Behavior of high resistance to $\mathrm{He}^{2+}$ induced irradiation damage in metallic glass, Nucl. Instrum. Meth. B. 312(2013) 84-89.

[14] W.J. Hou, X.X. Mei, Z.G. Wang, Y.N. Wang, Resistance to $\mathrm{He}^{2+}$ irradiation damage in metallic glass $\mathrm{Fe}_{80} \mathrm{Si}_{7.43} \mathrm{~B}_{12.57}$, Nucl. Instrum. Meth. B. 342(2015) 221-227.

[15] B. Wang, X.X. Mei, H.R. Zhang, W.J. Hou, Y.N. Wang, Z.G. Wang, C. Dong, Resistance to $\mathrm{He}^{2+}$ induced irradiation damage in metallic glass $\mathrm{Zr}_{64} \mathrm{Cu}_{17.8} \mathrm{Ni}_{0.7} \mathrm{Al}_{7.5}$, J. Nucl. Mater. 444(2014) 342-348.

[16] Q. Xu, K. Sato, T. Yoshiie, Nucleation of He bubbles in amorphous FeBSi alloy irradiated with He ions, Phil. Mag. Lett. 92(2012) 527-533.

[17] M.J. Norgett, M.T. Robinson, I.M. Torrens, A proposed method of calculating displacement dose rates, Nucl. Eng. Des. 33(1975) 50-54.

[18] D.J. Bacon, A.F. Calder, F. Gao, V.G. Kapinos, S.J. Wooding, Computer-simulation of defect production by displacement cascades in metals, Nucl. Instrum. Meth. B. 102(1995) 37-46.

[19] C.H. Zhang, J.S. Jang, Y.T. Yang, Y. Song, Y.M. Sun, H.D. Cho, Y.F. Jin, A study of the suppression of the high-temperature helium embrittlement in an oxide-particle dispersion strengthened alloy, Chin. Sci. Bull. 53(2008) 3416-3421.

[20] P. Trocellier, S. Agarwal, S. Miro, A review on helium mobility in inorganic materials, J. Nucl. Mater. 445(2014) 128-142.

[21] R.D. Daniels, Correlation of hydrogen evolution with surface blistering in proton-irradiated aluminum, J. Appl. Phys. 42(1971) 417.

[22] J.H. Evans, An interbubble fracture mechanism of blister formation on helium-irradiated metals, J. Nucl. Mater. 68(1977) 129-140.

[23] E. P. EerNisse, S. T. Picraux, Role of integrated lateral stress in surface deformation of He-implanted surfaces, J. Appl. Phys. 48(1977) 9-17.

[24] P. Murali, U. Ramamurty, Embrittlement of a bulk metallic glass due to sub-T-g annealing, Acta Mater. 53(2005) 1467-1478.

[25] Á. Révész, A. Concustell, L.K. Varga, S. Suriñach, M.D. Baró, Influence of the wheel speed on the thermal behaviour of $\mathrm{Cu}_{60} \mathrm{Zr}_{20} \mathrm{Ti}_{20}$ alloys, Mater. Sci. Eng. A. 375(2004) 776-780. 


\section{Special and High Performance Structural Materials}

10.4028/www.scientific.net/MSF.849

\section{Damage Characteristics of Zr-Based Metallic Glasses under Helium Ions Irradiation} 10.4028/www.scientific.net/MSF.849.22

\section{DOI References}

[1] W. Klement, R.H. Willens, P. Duwez, Non-crystalline structure in solidified gold-silicon alloys, Nature. 187(1960) 869-870.

$10.1038 / 187869 \mathrm{~b} 0$

[2] W.J. Weber, R.C. Ewing, C.A. Angell, G.W. Arnold, A.N. Cormack, J.M. Delaye, D.L. Griscom, L.W. Hobbs, A. Navrotsky, D.L. Price, A.M. Stoneham, W.C. Weinberg, Radiation effects in glasses used for immobilization of high-level waste and plutonium disposition, J. Mater. Res. 12(1997).

10.1557/jmr.1997.0266

[4] A. Greer, Y. Cheng, E. Ma, Shear bands in metallic glasses, Mater. Sci. Eng. R. 74(2013) 71-132. 10.1016/j.mser.2013.04.001

[5] M.D. Demetriou, M.E. Launey, G. Garrett, J.P. Schramm, D.C. Hofmann, W.L. Johnson, R.O. Ritchie, A damage-tolerant glass, Nat. Mater. 10(2011) 123-128.

$10.1038 /$ nmat 2930

[6] W.H. Wang, C. Dong, C.H. Shek, Bulk metallic glasses, Mater. Sci. Eng. R. 44(2004) 45-89.

10.1016/j.mser.2004.03.001

[7] A.G. Perez-Bergquist, H.B. Bei, K.J. Leonard, Y.W. Zhang, S.J. Zinkle, Effects of ion irradiation on Zr52. 5Cu17. 9Ni14. 6A110Ti5 (BAM-11) bulk metallic glass, Intermetallics. 53(2014) 62-66.

10.1016/j.intermet.2014.04.016

[8] X.N. Zhang, X.X. Mei, X. Ma, Y.M. Wang, J.B. Qiang, Y.N. Wang, Ar 12+ induced irradiation damage in bulk metallic glass (Cu47Zr45A18)98. 5Y1. 5, Chin. Phys. Lett. 32(2015) 026801.

$10.1088 / 0256-307 \mathrm{x} / 32 / 2 / 026801$

[9] F.Q. Gong, J. Wen, Y.J. Zhao, J.B. Qiang, Y.M. Wang, X.X. Mei, C. Dong, X.H. Wang, Stable reflectivity of bulk metallic glass mirrors for ITER optical diagnostic through an irradiation-induced selfrecovery mechanism, J. Nucl. Mater. 429(2012).

10.1016/j.jnucmat.2012.05.046

[10] Z. Hu, Z.Q. Zhao, Y.D. Wu, T. Lu, J.S. Xing, B.C. Wei, Surface features of Zr-based and Ti-based metallic glasses by ion irradiation, Vacuum. 89(2013) 142-146.

10.1016/j.vacuum.2012.03.006

[11] Z. Hu, Z.Q. Zhao, Y.P. Hu, J.S. Xing, T. Lu, B.C. Wei, Effect of ion irradiation on mechanical behaviors of Ti40Zr25Be30Cr5 bulk metallic glass, Mater. Res-Ibero-am. J. 15(2012) 713-717.

$10.1590 / \mathrm{s} 1516-14392012005000047$

[12] K. Morishita, R. Sugano, B.D. Wirth, MD and KMC modeling of the growth and shrinkage mechanisms of helium-vacancy clusters in Fe, J. Nucl. Mater. 323(2003) 243-250.

10.1016/j.jnucmat.2003.08.019

[16] Q. Xu, K. Sato, T. Yoshiie, Nucleation of He bubbles in amorphous FeBSi alloy irradiated with He ions, Phil. Mag. Lett. 92(2012) 527-533.

$10.1080 / 09500839.2012 .693635$

[18] D.J. Bacon, A.F. Calder, F. Gao, V.G. Kapinos, S.J. Wooding, Computer-simulation of defect production by displacement cascades in metals, Nucl. Instrum. Meth. B. 102(1995) 37-46. 
10.1016/0168-583x(95)80114-2

[19] C.H. Zhang, J.S. Jang, Y.T. Yang, Y. Song, Y.M. Sun, H.D. Cho, Y.F. Jin, A study of the suppression of the high-temperature helium embrittlement in an oxide-particle dispersion strengthened alloy, Chin. Sci. Bull. 53(2008) 3416-3421.

10.1007/s11434-008-0446-7

[20] P. Trocellier, S. Agarwal, S. Miro, A review on helium mobility in inorganic materials, J. Nucl. Mater.

445(2014) 128-142.

10.1016/j.jnucmat.2013.10.061

[21] R.D. Daniels, Correlation of hydrogen evolution with surface blistering in proton-irradiated aluminum, J. Appl. Phys. 42(1971) 417.

$10.1063 / 1.1659613$

[22] J.H. Evans, An interbubble fracture mechanism of blister formation on helium-irradiated metals, J. Nucl. Mater. 68(1977) 129-140.

10.1016/0022-3115(77)90232-x

[23] E. P. EerNisse, S. T. Picraux, Role of integrated lateral stress in surface deformation of He-implanted surfaces, J. Appl. Phys. 48(1977) 9-17.

10.1063/1.324309

[24] P. Murali, U. Ramamurty, Embrittlement of a bulk metallic glass due to sub-T-g annealing, Acta Mater. 53(2005) 1467-1478.

10.1016/j.actamat.2004.11.040

[25] Á. Révész, A. Concustell, L.K. Varga, S. Suriñach, M.D. Baró, Influence of the wheel speed on the thermal behaviour of Cu60Zr20Ti20 alloys, Mater. Sci. Eng. A. 375(2004) 776-780.

10.1016/j.msea.2003.10.151 
Reproduced with permission of the copyright owner. Further reproduction prohibited without permission. 